\title{
Data Envelopment Analysis for Relative Efficiency
}

\section{Measurement of Chinese Hospitals: A Systematic Review}

\author{
Siping Dong ${ }^{1}$, Yuling $\mathrm{Zuo}^{2}$, Shuyan Guo ${ }^{1}$, Meng $\mathrm{Li}^{1}$, Xinliang $\mathrm{Liu}^{3} \& \mathrm{Hao}^{\mathrm{Li}^{3 *}}$ \\ ${ }^{1}$ National Institute of Hospital Administration of PRC, Beijing, China \\ ${ }^{2}$ Puai Hospital, Tongji Medical College, Huazhong University of Science and Technology, Wuhan, \\ China \\ ${ }^{3}$ School of Health Sciences/Global Health Institute, Wuhan University, Wuhan, China \\ *Hao Li, E-mail: h.li@whu.edu.cn
}

Received: March 14, 2017

Accepted: March 21, 2017 Online Published: March 26, 2017

doi:10.22158/rhs.v2n2p79

URL: http://dx.doi.org/10.22158/rhs.v2n2p79

The work was sponsored by the National Nature Science Foundation of China (Granted No. 71573061), the Scientific Research Foundation for the Returned Overseas Chinese Scholars of State Education Ministry of China [Jiao Wai Si Liu, 2015(No.1098)], and Hubei Provincial Health and Family Planning Commission Young Talent Grant (2016-2017, No.WJ2017Q003).

\begin{abstract}
The purpose was to explore the gap between China and the international world in efficiency measurement of hospitals with Data Envelopment Analysis, and to improve the standardization of healthcare efficiency measurement in China. A systematic review was conducted using appropriate search strategies. Studies were included containing DEA approaches regarding general hospital efficiency, published in international literature and in both Chinese and English about Chinese hospitals from January 2004 to October 2014. The results showed that statistical significances were found in indicators such as number of DMUs, percentage of allocative efficiency studies, ratio of studies with multiple years, number of studies with monetary indicators in input and output sets, etc. The statistical insignificance in some indicators such as the number of input and output indicators were also found among China, Europe, USA and others. Some problems were found in current DEA-based hospital efficiency studies in China, such as inappropriate selection of input-output indicators, no bias-correction on efficiency scores, etc. The standardization of DEA methods applied in China's hospital efficiency research needs to be improved. Chinese researchers should pay more attention to latest international research findings, so as to keep pace with the cutting edge hospital efficiency research.
\end{abstract}




\section{Keywords}

Data Envelopment Analysis (DEA), hospital efficiency, international comparison, China

\section{Introduction}

Since the implementation of the new round of health system reforms in China in 2009, a considerable amount of achievements have been made, such as the establishment of a combination of basic health insurance programs with universal coverage to reduce the share of out-of-pocket health spending. With population aging as well as the increase in income, Chinese people have more healthcare needs and demands. In this context, all kinds of public hospitals are going for massive expansion, such as achieving medical alliance among hospitals, expanding present site, building branch hospitals, etc. How to improve the technical efficiency of hospitals to achieve economy of scale is significant not only to hospital development, but also to better meet the increasing healthcare needs and demands.

In terms of hospital efficiency measurement, the parametric method represented by Stochastic Frontier Analysis (SFA) and the nonparametric method represented by Data Envelopment Analysis (DEA) have been widely applied. The SFA method was once applied to analysis the hospital inefficiency (Rosko \& Mutter, 2008). Although the advantages of SFA were well documented, its potential drawbacks for hospital efficiency are obvious as well, such as the necessity to estimate production functions, using one single output, etc. In contrast, the DEA approach can simultaneously accommodate multiple inputs and multiple outputs (Banker, Charnes, \& Cooper, 1984; Charnes, Cooper, \& Rhodes, 1979), which has been considered as an effective and flexible tool for hospital efficiency measurement (O'Neill, Rauner, Heidenberger, \& Kraus, 2008). DEA can be easily used to calculate hospital efficiency scores based on appropriate selection of input-output indicators.

Chinese researchers have applied DEA models for more than two decades in efficiency measurement of healthcare organizations. Lots of articles have been published in Chinese journals. However, it is surprising to find that only very few ones has been published in international journals. Besides language barriers there must be some confounding reasons. The purpose of this study is to explore the gap between China and the international world in efficiency measurement of healthcare organizations with DEA, and to improve the standardization of efficiency measurement of hospitals in China.

\section{Method}

\subsection{Design of the Study}

This research is designed to classify the literature into China, Europe, USA and other countries and regions. First, the literature was grouped into Chinese literature and international literature. Then the two respective groups of literature were further decomposed into technical efficiency and allocative efficiency. After that the literature was further grouped according to whether multiple time periods applied. The essential features of each paper was summarized in terms of input indicators, output indicators, type of efficiency, number of DMUs, DMU-indicator ratio, etc. The literature about China 
was further compared with the international literature (Europe, USA and other countries and regions) to explore the differences across nations and regions.

In further design, the input and output indicators would be addressed respectively. The input indicators would be classified into four categories: beds, staffs, monetary indicators and other input indicators; the output indicators were classified into 3 categories: services indicators, monetary indicators and other output indicators. In order to evaluate the standardization of indicators applied in China, the input-output indicators were counted of their citation numbers and percentage.

\subsection{Literature Searching and Collection}

Formula "Title $=($ 'hospitals') $*$ Abstract $=$ ('data envelopment analysis' + 'DEA')" was employed to search the literature published between January, 2004 and October, 2014. Comprehensive literature searches were conducted through typical Chinese and English online databases, such as CNKI China Academic Journals Full-text Database, Wanfang Database, Chongqing VIP Chinese Scientific Journals Database, Chinese Biomedical Literature Database and Academic Search Complete (EBSCO), Web of Knowledge, Springer Link, PubMed, etc. Besides, since the focus of this review was on the study of general hospitals efficiency, articles on specialty hospitals and military hospitals were excluded. And studies on DEA-based hospital efficiency in Taiwan were excluded in our study. As a result, 75 DEA-based hospital efficiency articles in China.

\subsection{Data Analysis}

Descriptive analysis was applied for both the classification of collected articles and the selection of input and output indicators. In order to recognize gaps between the differences among China and international studies, variance analysis and chi-square test were used to test the statistical significances between China and other countries and regions on key variables such as number of DMUs, number of input and output indicators, ratio of studies on allocative efficiency, ratio of multiple-year studies, DMU-indicator ratio greater than 3, number of studies with monetary indicators in both input and output sets, etc.

\section{Results}

\subsection{Description of Method Classification of Hospital Efficiency Studies}

Each of the 7 groups can be summarized as follows: Figure 1 shows 3 classified groups of the studies in China: technical efficiency with single year period (Group 1), technical efficiency with multiple periods (Group 2) and allocative efficiency with multiple periods (Group 3). Figure 2 shows 4 groups of the international articles: technical efficiency with single period (Group 4), technical efficiency with multiple periods (Group 5), allocative efficiency with single period (Group 6), and allocative efficiency with multiply periods. Each of the 7 groups can be summarized as follows: 


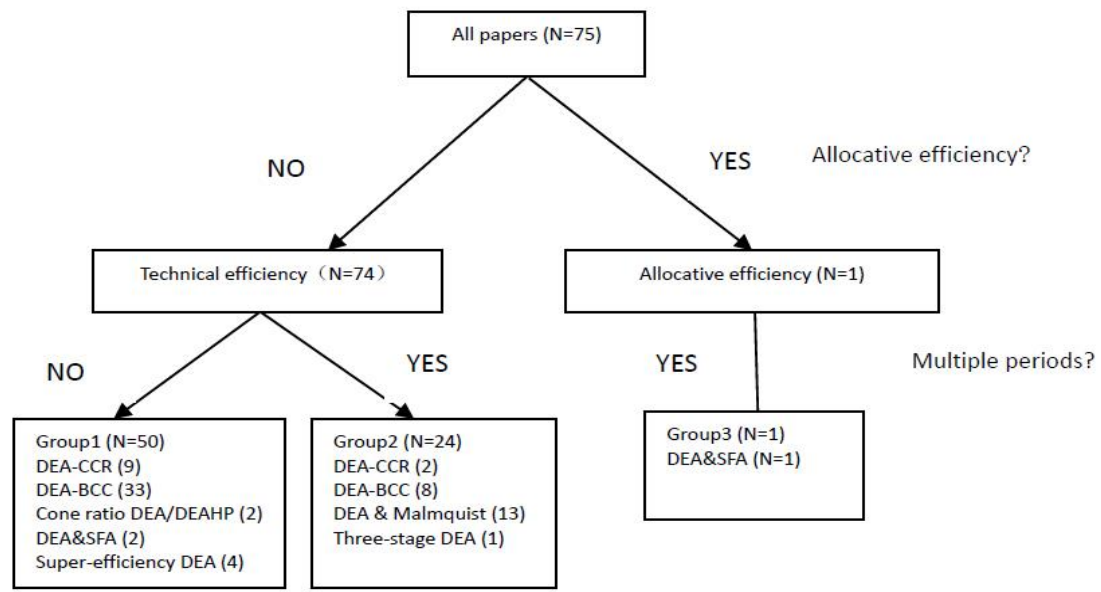

Figure 1. Classification of DEA-Based Hospital Efficiency Studies in PRC

\section{Group 1:}

The majority of hospital efficiency studies (32 out of 51 studies) in China concentrate on the application of classical DEA models (CCR and BCC). Cone ratio DEA (Luo et al., 2004) and DEAHP (Xia et al., 2009) in combination with classical DEA models and AHP were used in 2 studies. Super-efficiency model was also employed to determine the relative efficiency of effective DMUs measured (Liu et al., 2011; Wang \& Pan, 2013; Yu et al., 2012; Zhou, 2013).

\section{Group 2:}

13 studies in China applied Malmquist-DEA. It was found that super-efficiency model was employed to analyze the efficiency of hospitals with multiple time periods. In addition, a three-stage DEA based Malmquist productivity index adopted by Yang and Zeng (2014) was used to measure the changes in productivity, efficiency and quality (Yang \& Zeng, 2014). Initial DEA, SFA regression and re-compute efficiency was applied in the three-stage DEA.

\section{Group 3:}

Allocative efficiency measurement was found just in one study. 340 public hospitals of and above county level in Sichuan province, China from 2003-2007 were taken as the study example by Zhong (2010) in his master thesis to estimate technical, scale, cost and allocative efficiency with DEA and SFA methods (Zhong, 2010). 


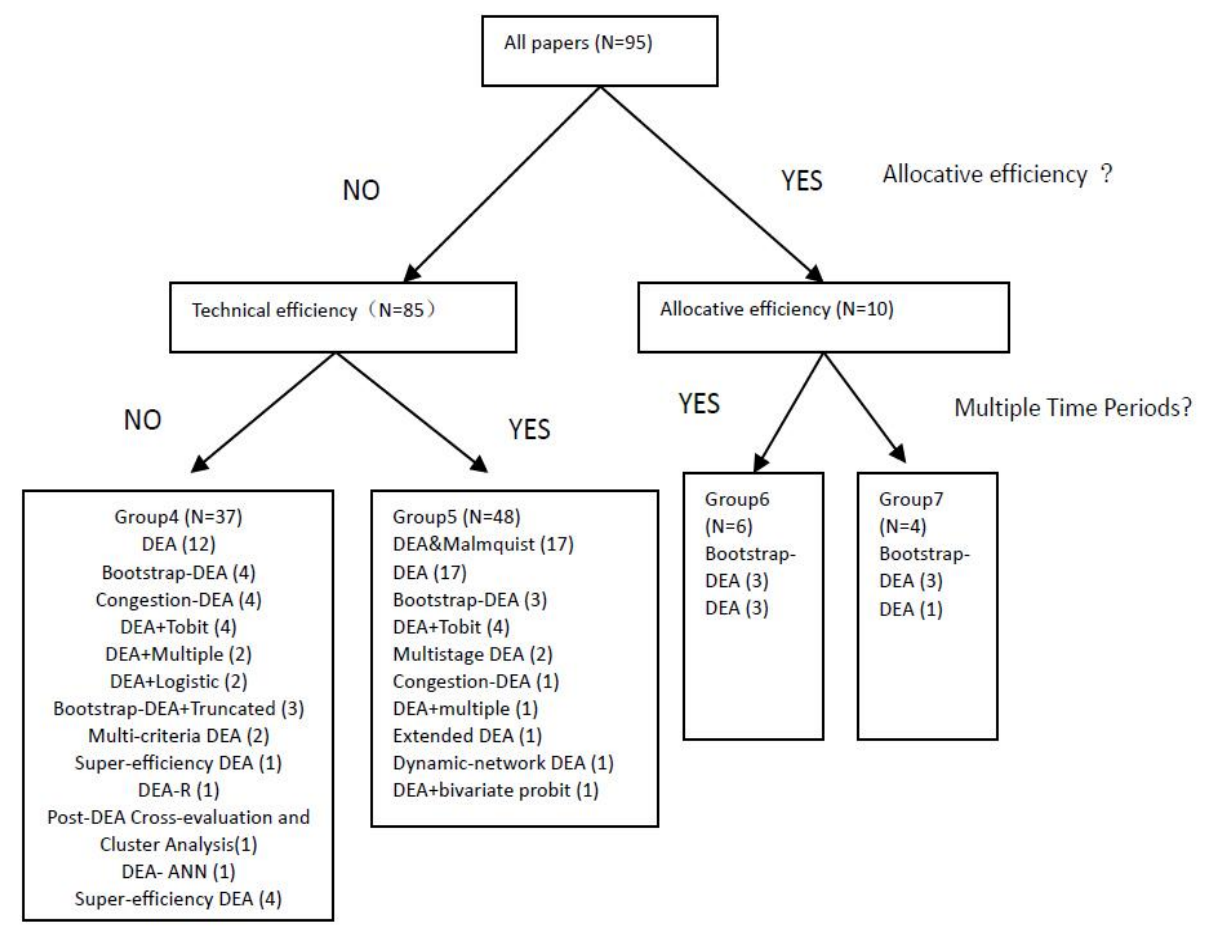

Figure 2. Classification of DEA-Based Hospital Efficiency Studies in International Studies

\section{Group 4:}

A common practice has been made to measure efficiency in two stages in the literature. Novel applications and extensions of efficiency measurement in two stages includes DEA with Tobit (Fareed et al., 2012; Kirigia \& Asbu, 2013; Nayar et al., 2013), multiple (Bates et al., 2006; Gok \& Sezen, 2013), logistic (Chustz, 2012; Lobo et al., 2014) and truncated regression analysis (Araujo et al., 2014; Halkos \& Tzeremes, 2011; Kounetas \& Papathanassopoulos, 2013; Mitropoulos et al., 2013), etc. Furthermore, a considerable extended DEA models have been developed in international studies, including bootstrap-DEA (Halkos \& Tzeremes, 2011; Puenpatom \& Rosenman, 2008; Simões \& Marques, 2011; Varabyova \& Schreyogg, 2013), congestion-DEA (Ferrier et al., 2006; Masiye, 2007; Valdmanis et al., 2004; Valdmanis et al., 2008), DEA-R (Wei et al., 2011), post DEA cross-evaluation and cluster analysis (Flokou et al., 2011), and multi-criteria DEA models (Ajlouni et al., 2013; Zaim et al., 2007), etc.

\section{Group 5:}

Some studies adopted panel data to measure hospital efficiency with DEA and other techniques such as Malmquist index, bootstrap, etc. To measure both efficiencies of separate DMUs and dynamic efficiency changes, dynamic-network DEA was applied in the efficiency evaluation in the healthcare field (Kawaguchi et al., 2014). DEA and bivariate probit was explored to examine the effects of environmental pressures on hospital efficiency and uncompensated care provision (Hsieh et al., 2010).

\section{Group 6 and Group 7:}

Due to the difficulty to obtain rational price information, studies on allocative efficiency were scant.

Only 2 main approaches, standard DEA model and Bootstrap-DEA, were used to calculate the allocative 
efficiency of hospitals in the literature (Besstremyannaya, 2013; Blank \& Valdmanis, 2010; Blank \& Vanhulst, 2011; Gautam et al., 2013; Kristensen et al., 2010; Linna et al., 2006, 2010; Ma \& Petr, 2005; Medin et al., 2011; Nedelea \& Fannin, 2013).

\subsection{Selection of Input Indicators}

The input indicators of DEA-based technical efficiency studies in China and abroad were addressed respectively. The results showed that the top 5 input indicators applied in China were "actual number of beds/actual number of open beds/average number of beds" (93.24\%), "total expenses/operating expenses/supplies" (62.16\%), "fixed assets" (55.41\%), "number of total FTEs/staff/labor size" (39.19\%), and "medical technical staffs" (22.97\%). The top 5 input indicators applied in international literature were "number of beds" (60.92\%), "number of physicians/doctors" (35.63\%), "number of nurses and/or nursing staff” (28.74\%), "operating expenses/supplies" (27.59\%), and "number of total FTEs/staff/labor size" (18.39\%). In order to deal with the variety of input indicators, 4 sub-categories were summarized: "beds", "labors", "monetary indicators" and other atypical input indicators. Table 1 lists the input indicators based on literature on hospital technical efficiency.

Table 1. Input Indicators Based on International Literature and PRC

\begin{tabular}{|c|c|c|c|c|}
\hline \multirow[t]{2}{*}{ Input indicators } & \multicolumn{2}{|c|}{ International literature } & \multicolumn{2}{|l|}{ PRC } \\
\hline & $\begin{array}{l}\text { Citation } \\
\text { number }\end{array}$ & $\begin{array}{l}\text { Percentage } \\
(\%)\end{array}$ & $\begin{array}{l}\text { Citation } \\
\text { number }\end{array}$ & $\begin{array}{l}\text { Percentage } \\
(\%)\end{array}$ \\
\hline \multicolumn{5}{|l|}{ Beds } \\
\hline $\begin{array}{l}\text { Number of beds/number of active beds/average } \\
\text { number of beds }\end{array}$ & 58 & 68.24 & 69 & 93.24 \\
\hline Number of acute/emergency beds & 4 & 4.71 & & \\
\hline Number of staffed beds & 4 & 4.71 & 1 & 1.35 \\
\hline Number of ICU beds & 1 & 1.18 & & \\
\hline Number of bed days & 2 & 2.35 & & \\
\hline $\begin{array}{l}\text { Number of beds for treatments for dermatitis } \\
\text { herpetiformis }\end{array}$ & 2 & 2.35 & & \\
\hline Number of general beds and special beds & 2 & 2.35 & & \\
\hline Number of other beds & 1 & 1.18 & & \\
\hline \multicolumn{5}{|l|}{ Staffs } \\
\hline Number of total FTEs/staff/labor size & 16 & 18.82 & 29 & 39.19 \\
\hline Number of physicians/doctors & 37 & 43.53 & 11 & 14.86 \\
\hline Number of FTE physicians and dentists & 4 & 4.71 & & \\
\hline Number of specialist physicians & 3 & 3.53 & 1 & 1.35 \\
\hline Number of physicians and nurses & 3 & 3.53 & & \\
\hline Number of FTE interns/residents & 3 & 3.53 & 1 & 1.35 \\
\hline Number of pharmacists & 3 & 3.53 & & \\
\hline Number of nurses and/or nursing staff & 30 & 35.29 & 9 & 12.16 \\
\hline Number of FTE registered nurses & 8 & 9.41 & & \\
\hline Number of FTE licensed practical nurses & 6 & 7.06 & & \\
\hline Number of clinical/medical/health staff & 7 & 8.24 & & \\
\hline Number of other medical/health professionals & 4 & 4.71 & & \\
\hline
\end{tabular}




$\begin{array}{lllll}\text { Number of other staff } & 15 & 17.65 & 2 & 2.70 \\ \text { Number of other nonclinical staff } & 5 & 5.88 & & \\ \text { Number of administrative staff } & 4 & 4.71 & 4 & 5.41 \\ \text { Number of medical technical staffs } & 3 & 3.53 & 17 & 22.97 \\ \text { Number of other professions } & 3 & 3.53 & & \\ \text { Monetary indicators } & & & & \\ \text { Total expenses/Operating expenses/Supplies } & 24 & 28.24 & 46 & 62.16 \\ \text { Total assets } & & & 4 & 5.41 \\ \text { Fixed assets } & & & 41 & 55.41 \\ \text { Expenditures on materials, supplies, and } & 7 & 8.24 & & \\ \text { drugs/material expenses/drugs other supplies } & 3 & 3.53 & 2 & 2.70 \\ \text { Total equipment expense/Total facility expense } & 2 & 2.35 & & \\ \text { Subsidy from municipal/allowance expenditures } & 2 & 2.35 & 2 & 2.70 \\ \text { Capital expenses } & 2 & & 3 & 4.05 \\ \text { Total hospitalization costs } & & & \end{array}$

\section{Beds}

70 out of 74 studies in China adopted number of beds as an input indicator. Some studies used "actual number of beds/actual number of open beds/average number of beds" (used in 69 studies), "number of staffed beds" (only used in 1 study) instead. Table 1 lists the bed indicators based on international literature on hospital efficiency. The "number of beds" was regarded as an input indicator in 53 out of 77 technical efficiency international studies. Several studies disaggregated hospital beds into acute/emergence beds, Intensive Care Unit (ICU) beds, general beds and special beds, etc.

\section{Labors}

In our study, labor indicators were adopted in 71 China studies and in 72 international studies. $39.19 \%$ studies in China used "number of total FTEs (full-time employees)" as an input indicator, followed by "medical technical staffs" $(22.97 \%)$ and "number of physicians" $(14.86 \%)$ respectively. As is seen in

Table 1, some typical labor indicators were widely applied in international studies, such as "number of physicians/doctors" (35.63\%), "number of nurses/nursing staff" (28.74\%), "number of total FTEs/staff/labor size" (18.39\%) and "other staff” (16.09\%).

\section{Monetary indicators}

62 out of 74 hospital technical efficiency measurement studies in China defined monetary indicators (fixed asset, expenditure, revenue) into the input set, while 30 international studies had the same consideration (See Table 1). Various types of monetary indicators in the input set in China were divided into the following sub-categories: operating expenses and capital investment, labor costs and equipment expenses. 46 studies presented "total expenses/operating expenses/supplies" as the cost input, while "fixed assets" were employed as input categories in 41 studies. "Medical staff costs" and "total equipment expenses" are used as a proxy of labor costs and equipment expenses respectively.

\section{Other atypical input indicators}

Statistics showed that in several hospital technical efficiency studies in China, some atypical input 
indicators were added, such as "building area", "average medical costs of discharges", while the international literature introduced "staff hours" and/or "service complexity" as input indicators.

\subsection{Output Indicators}

Output indicators of 74 DEA-based hospitals technical efficiency studies in China and 77 international studies were counted respectively, which were classified into 3 sub-categories: "medical service indicators", "monetary indicators" and other atypical indicators. The results indicate that the top five output indicators in China were "number of discharges" (79.73\%), "number of outpatient and emergency visits" (51.35\%), "operating revenues" (29.73\%), "bed turnover rate/bed turnover times" (25.68\%) and "number of total visits" $(21.62 \%)$. It turns out that, according to our statistics, the top five output indicators in international studies were "number of outpatient visits" (40.23\%), "number of total surgeries" (21.84\%), "number of inpatient days" (19.54\%), "total patient days" (10.34\%), "number of discharges" (10.34\%). Table 2 lists the output indicators based on literature on hospital technical efficiency.

Table 2. Output Indicators Based on International Literature and PRC

\begin{tabular}{lllll}
\hline \multirow{2}{*}{ Output indicators } & \multicolumn{3}{l}{ International literature } & PRC \\
\cline { 2 - 5 } & $\begin{array}{l}\text { Citation } \\
\text { number }\end{array}$ & $\begin{array}{l}\text { Percentage } \\
(\%)\end{array}$ & $\begin{array}{l}\text { Citation } \\
\text { number }\end{array}$ & $\begin{array}{l}\text { Percentage } \\
(\%)\end{array}$ \\
\hline Medical service & & & & \\
Number of total visits & 8 & 9.41 & 16 & 21.62 \\
Number of outpatient and emergency visits & & & 38 & 51.35 \\
Number of outpatient visits & 39 & 45.88 & 11 & 14.86 \\
Number of emergency visits & 8 & 9.41 & 2 & 2.70 \\
Total patient days & 12 & 14.12 & & \\
Number of inpatient days & 18 & 21.18 & & \\
number of inpatients & 7 & 8.24 & & \\
Number of discharges & 11 & 12.94 & 59 & 79.73 \\
Number of adjusted admissions & 6 & 7.06 & & \\
Number of total surgeries & 20 & 23.53 & 5 & 6.76 \\
Surgical patients & 5 & 5.88 & 3 & 4.05 \\
Bed turnover rate/bed turnover times & & & 19 & 25.68 \\
Average length of stay & & & 14 & 18.92 \\
Number of actual bed-days occupied & & & 7 & 9.46 \\
Monetary indicators & & & & \\
Total revenues & 1 & 1.18 & 14 & 18.92 \\
Operating revenues & 2 & 2.35 & 22 & 29.73 \\
Medical revenues & 2 & 2.35 & 7 & 9.46 \\
Medical revenues of outpatient & & & 3 & 4.05 \\
Medical revenues of inpatient & & & 3 & 4.05 \\
Subsidy & & & 1.18 & 1.35 \\
Revenues on drugs & & & & 2.70 \\
\hline & & & & \\
\hline
\end{tabular}




\section{Medical service indicators}

Medical service indicators as output indicators were involved in the vast majority of studies (73 in China and 72 international studies), which were classified into three sub-categories: volume of outpatient and emergency, volume of inpatient and volume of surgeries. First, these indicators, number of outpatient and emergency visits (38 studies) and number of discharges (59 studies), are commonly included as an output factors in DEA-based hospital efficiency studies in China. However, studies in abroad often distinguished between "number of outpatient visits" and "number of emergency visits". It was noted that number of inpatient days were defined as the output in DEA-based efficiency estimation in international studies.

\section{Monetary indicators}

Only a small number of international studies, about 5 out of 77, employed monetary indicators in their output set. Conversely, these indicators were considered as output indicators in majority of DEA-based hospital technical efficiency studies (48 in 74) in China, as shown in Table 2. Whereas, different indicators measuring revenues, such as "total revenues", "operating revenues" and "medical revenues" in hospitals were adopted among related studies of China.

\section{Other atypical indicators}

Atypical indicators were found in both Chinese and international studies. Some studies of China added "expenditures on materials and drugs per bed", "equivalent volume of diagnostics per physician", "expenditures per equivalent" to their output set. The international literature used "mortality rate", "FTE trainees" and "number of deliveries".

\subsection{International Comparison}

Studies were classified into four groups based on their country of origins: China $(n=75)$, Europe $(n=29)$, USA $(n=29)$ and other countries and regions $(n=29)$. Table 3 indicates statistical significances of differences in number of DMUs, ratio of studies of allocative efficiency, ratio of studies with No. of DMUs/No. of indicators 3, ratio of studies with multiple periods, number of studies with monetary indicators in the input set and number of studies with monetary indicators in the output set. No statistical differences in number of input indicators and number of output indicators were observed among the four groups.

Table 3. International Comparison of DEA-Based Hospital Efficiency Studies

\begin{tabular}{|c|c|c|c|c|c|c|c|c|}
\hline & PRC & Europe & USA & $\begin{array}{l}\text { Other } \\
\text { countries } \\
\text { and regions }\end{array}$ & $\mathrm{P}$-value & $\begin{array}{l}\text { Difference: } \\
\text { PRC-Europe }\end{array}$ & $\begin{array}{l}\text { Difference: } \\
\text { PRC-America }\end{array}$ & $\begin{array}{l}\text { Difference: PRC-other } \\
\text { countries and regions }\end{array}$ \\
\hline Number of studies & 75 & 29 & 29 & 37 & & & & \\
\hline Number of DMUs & 103.73 & 344.56 & 630.76 & 296.49 & 0.000 & $\begin{array}{l}-240.83 \\
p=0.333\end{array}$ & $\begin{array}{l}-527.03 \\
p=0.000\end{array}$ & $\begin{array}{l}-192.76 \\
p=0.052\end{array}$ \\
\hline Number of output indicators & 3.52 & 3.13 & 3.41 & 3.65 & 0.136 & - & - & - \\
\hline Ratio of studies of allocative & 1.33 & 24.14 & 6.90 & 2.70 & 0.000 & $-22.81 \%$ & $-5.57 \%$ & $-1.33 \%$ \\
\hline
\end{tabular}




\begin{tabular}{|c|c|c|c|c|c|c|c|c|}
\hline efficiency (\%) & & & & & & $\mathrm{p}=0.000^{*}$ & $\mathrm{p}=0.187^{*}$ & $\mathrm{p}=1.000^{*}$ \\
\hline $\begin{array}{l}\text { Ratio of studies with No. of } \\
\text { DMUs/indicators } \geq 3(\%)\end{array}$ & 77.33 & 100 & 96.55 & 100 & 0.000 & $\begin{array}{l}-22.67 \% \\
p=0.016^{*}\end{array}$ & $\begin{array}{l}-19.22 \% \\
p=0.020 *\end{array}$ & $\begin{array}{l}-22.67 \% \\
p=0.002 *\end{array}$ \\
\hline $\begin{array}{l}\text { Ratio of multiple period } \\
\text { studies }(\%)\end{array}$ & 33.33 & 51.72 & 62.07 & 51.35 & 0.034 & $\begin{array}{l}-18.42 \% \\
P=0.115^{*}\end{array}$ & $\begin{array}{l}-28.77 \% \% \\
P=0.014 *\end{array}$ & $\begin{array}{l}-18.05 \% \\
p=0.066^{*}\end{array}$ \\
\hline $\begin{array}{l}\text { Number of studies with } \\
\text { monetary indicators in the } \\
\text { input set } \S\end{array}$ & $62(74)$ & $10(22)$ & $12(27)$ & $15(36)$ & 0.000 & $0.001^{*}$ & $0.000 *$ & $0.000^{*}$ \\
\hline $\begin{array}{l}\text { Number of studies with } \\
\text { monetary indicators in the } \\
\text { output set } \S\end{array}$ & $48(74)$ & $0(22)$ & $2(27)$ & $4(36)$ & 0.000 & $0.000^{*}$ & $0.000 *$ & $0.000 *$ \\
\hline
\end{tabular}

$* \alpha=0.0125$, others: $\alpha=0.05$; “-” As insignificant difference was found in four groups, no further pair-wise comparisons were made. §Just for technical efficiency studies.

Statistics showed that the number of studies in the USA were more than that of China in the number of DMUs (628.34 VS 103.73, $\mathrm{p}=0.069)$. Compared with China studies, the European studies measured more allocative efficiency $(24.14 \%$ VS $1.33 \%, p=0.000)$. However, no statistical differences between China and USA, other countries and regions in ratio of allocative efficiency were found. According to some researchers, the sample should have at least three times as many DMUs as the total number of input and output indicator (Banker et al., 1984; Banker, Charnes, Cooper, \& Clarke, 1989; Banker, Charnes, Cooper, \& Schinnar, 1981; O’Neill et al., 2008). Statistical differences were detected between China and Europe, other countries and regions $(100 \%$ VS $77.33 \%, p=0.012)$, and no studies in Europe, other countries and regions had a ratio of less than three observations per indicator. The results demonstrated significant differences in ratio of studies of multiple period between China and USA was detected (33.33\% VS 62.07\%, $\mathrm{p}=0.008)$. Our results revealed statistical significances in number of studies with monetary indicators in the input and output set (technical efficiency studies) between China, Europe, USA and other countries and regions. Moreover, due to monetary indicators in the input set, China had significantly more number of studies than Europe (62 VS 10, $\mathrm{p}=0.001$ ), USA (62 VS 12, p =0.000), and other countries and regions (62 VS 8, p = 0.000), and so is the number of studies with monetary indicators in the output set, which show statistical significances between China and Europe (48 VS 0, p = 0.000 ),USA (48 VS $2, p=0.000$ ) and other countries and regions (48 VS $3, p=0.000$ ).

\section{Discussion}

Based on above classification and comparison, some typical problems existing in DEA-based healthcare efficiency studies in China can be summarized and discussed as follows:

\subsection{Lack of Allocative Efficiency Research}

Allocative efficiency measurement requires that the price information of each input indicator should be known. However, due to the difficulty to obtain price information, few Chinese studies focus on allocative efficiency. Only one article was about allocative efficiency, far less than the number of technical efficiency studies (Zhong, 2010). In comparison, the European and American studies focused 
more on allocative efficiency, indicating significant differences with China. More hospital reforms in price transparency together with regional health information platform need to be conducted so that it will be easier for Chinese researchers to get the price information for allocative efficiency research.

\subsection{Application of Simple Classical Models in Technical Efficiency Measurement}

In the Chinese studies, CCR, BCC, Malmquist index, super-efficiency, cone-ratio, two-stage DEA, three-stage DEA, etc. were found. In comparison, more diversified models have been employed in international studies, such as Bootstrap-DEA, Congestion-DEA, two-stage DEA, three-stage DEA, Dynamic-network DEA, post-DEA Cross-evaluation and Cluster Analysis, DEA-R model, etc. It can be seen that, big gap exists between China and the international world in the number of DEA models applied and the former mainly applied simple classical models in technical efficiency and productivity measurement. More in-depth analysis should be in place so as to update current DEA models from recent international findings and improve the standardization of DEA-based healthcare efficiency research in China.

\subsection{Inappropriate Selection of Monetary Indicators in Technical Efficiency Measurement}

It is common that several monetary indicators, such as "total revenue/operating expenses/medical expenses", "fixed assets", etc. have been selected as input/output indicators in Chinese hospital efficiency measurement, while few international studies have done so. When estimating technical efficiency, very few monetary indicators were included into output indicators in international studies. However, significant differences were found in number of studies with monetary indicators in the output set between China, Europe, USA and other countries and regions. In our study, only 26 of 74 studies in China did not adopt monetary indicators as output ones. Li et al. (2014) held that monetary indicators should not be considered as an output (Li et al., 2014), so as to avoid the violation of technical and allocative efficiency. However, monetary indicators can be used as input indicators to measure cost efficiency. The mixing of indicators including both monetary and volume indicators have been applied in many Chinese studies, leading to double count and violation of both technical and allocative efficiency.

\subsection{Inappropriate Application of Ratio Indicators}

As it is well known, DEA is based on linear programming of direct inputs and outputs for optimal arrangement of production. In many Chinese studies ratio indicators such as bed occupancy rate, hospitalization days, etc. were included into output indicators, which were inappropriate in DEA efficiency measurement. However, these ratio indicators can be considered as process variables rather than direct output indicators to help researchers better understand efficiency and productivity improvements. It is important for Chinese researchers to select input and output indicators in accordance with general international standards to improve the international recognition of DEA-based healthcare efficiency research conducted by Chinese researchers.

\subsection{Less Attention to Number of DMUs}

According to some studies, one requirement to apply DEA is that the number of DMUs should be at least 
3 times than the total number of input and output indicators. If the condition cannot be met in the research, more efficient DMUs in DEA (efficiency scores equals 1) will be counted, which is relatively inaccurate. It was found that this requirement was met in most of international studies. In comparison, 17 Chinese studies did not comply with the condition in these investigated studies. Therefore, Chinese researchers need pay more attention to the number of DMUs to improve the rationality and science of DEA-based hospital efficiency research. When the number of DMUs is too small, one solution is to apply Bootstrap-DEA method to amplify the number of DMUs by sampling with replacement from the original sample to get the bootstrap sample.

\subsection{Lack of Bias-Correction to Efficiency Scores}

It is well known that classical DEA models such as CCR, BCC, Malmquist index, etc. did not consider the impact of environmental and random factors on efficiency scores. The estimated efficiency scores should be biased. Simar and Wilson introduced Bootstrap method to improve the accuracy of efficiency estimation with DEA (Simar \& Wilson, 1998). The method can be used to estimate confidence intervals of efficiency scores and allow the use of bias correction in central estimates to statistically test significant differences in efficiency levels (Daraio \& Simar, 2007). However, no Bootstrap-DEA literature has been found in DEA-based healthcare efficiency studies in China. This gap was found by Li et al. (2014) and later on the authors Li and Dong (2015) introduced the bootstrap method from international literature to fill the gap. In future study, this method is recommended to be applied in various healthcare institutions with homogeneity in their relative efficiency measurement with DEA. Moreover, it can be anticipated that there is ample room for the combined application of classical DEA models with Bootstrap technique.

\section{Conclusions}

In our review study, we have found substantial gap between China and international world in healthcare efficiency measurement with DEA. Besides the need for more allocative efficiency research, the standardization of Chinese research in technical efficiency measurement of hospitals should be further improved, specifically: (1) The selection of input and output indicators should be met the same standards as required by international studies to avoid the mixing of volume indicators with monetary and ratio indicators; (2) The number of DMUs should be 3 times more than that of input and output indicators; (3) Bootstrap-DEA should be urgently introduced into current research to correct the bias and improve the accuracy of efficiency scores; (4) Current two-stage and three-stage DEA models need to combined with the Bootstrap-DEA method to further improve the accuracy of efficiency scores. It is advised that Chinese researchers should pay more attention to study latest international research findings, so as to keep pace with the cutting edge hospital efficiency research.

\subsection{List of Abbreviations}

DEA: Data Envelopment Analysis; DMU: Decision-making Unit; SFA: Stochastic Frontier Analysis; CNKI: China National Knowledge Infrastructure; DEAHP: Data Envelopment Analysis and Analytic 
Hierarchy Process; AHP: Analytic Hierarchy Process; ANN: Artificial Neural Network; FTE: Full Time Employee; ICU: Intensive Care Unit; PRC: the People's Republic of China; USA: the United States of America.

\subsection{Contributions}

Dong, S. P. and Zuo, Y. L. have equal contributions in writing the manuscript. Li, H. contributes to the review design framework, discussion, and perfection of the manuscript. Guo, S. Y. and Li, M. contribute to article collection and preliminary analysis. Liu, X. L. contributes in the discussion for improvement of the final manuscript.

\section{Acknowledgements}

We would like to thank the reviewers and other readers for their comments to improve the quality of this article.

\section{References}

Ajlouni, M. d. M., Zyoud, A., Jaber, B., Shaheen, H., Al-Natour, M., \& Anshasi, R. J. (2013). The Relative Efficiency of Jordanian Public Hospitals Using Data Envelopment Analysis and Pabon Lasso Diagram. Global Journal of Business Research (GJBR), 7, 59-72.

Aletras, V., Kontodimopoulos, N., Zagouldoudis, A., \& Niakas, D. (2007). The Short-term Effect on Technical and Scale efficiency of Establishing Regional Health Systems and General Management in Greek NHS Hospitals. Health Policy, 83, 236-245. https://doi.org/10.1016/j.healthpol.2007.01.008

Almeida, A., \& Fique, J. (2011). Evaluating hospital efficiency adjusting for quality indicators: An application to Portuguese NHS hospitals (Working Papers (FEP), pp. 1-20). Universidade do Porto.

Ao, J. G., \& Yuan, J. (2009). An Application of Data Envelopment Analysis to Large Public Hospitals Efficiency Evaluation. Health Economics Research, 34-37.

Araujo, C., Barros, C. P., \& Wanke, P. (2014). Efficiency determinants and capacity issues in Brazilian for-profit hospitals. Health Care Management Science, 17, 126-138. https://doi.org/10.1007/s10729-013-9249-8

Asmild, M., Hollingsworth, B., \& Birch, S. (2013). The scale of hospital production in different settings: One size does not fit all. Journal of Productivity Analysis, 40, 197-206. https://doi.org/10.1007/s11123-012-0332-9

Banker, R. D., Charnes, A., \& Cooper, W. W. (1984). Some Models for Estimating Technical and Scale Inefficiences in Data Envelopment Analysis. Management Science, 30, 1078-1092. https://doi.org/10.1287/mnsc.30.9.1078

Banker, R. D., Charnes, A., Cooper, W. W., \& Clarke, R. (1989). Constained game formulations and interpretations for data envelopment analysis. European Journal of Operational Research, 40, 
299-308. https://doi.org/10.1016/0377-2217(89)90422-0

Banker, R. D., Charnes, A., Cooper, W. W., \& Schinnar, A. P. (1981). A bi-extremal principle for frontier estimation and efficiency evaluations. Management Science, 27, 1370-1382. https://doi.org/10.1287/mnsc.27.12.1370

Bao, Y. R., Sai, X. Y., \& Liu, L. H. (2012). Application on Regional Health Planning and Micro-economic Method in the Calculation of Hospital Beds. Chinese Hospitals, 16, 17-19.

Barbetta, G. P., Turati, G., \& Zago, A. M. (2007). Behavioral differences between public and private not-for-profit hospitals in the Italian National Health Service. Health Economics, 16, 75-96. https://doi.org/10.1002/hec.1143

Barnum, D. T., Walton, S. M., Shields, K. L., \& Schumock, G. T. (2011). Measuring Hospital Efficiency with Data Envelopment Analysis: Nonsubstitutable vs. Substitutable Inputs and Outputs. Journal of Medical Systems, 35, 1393-1401. https://doi.org/10.1007/s10916-009-9416-0

Bates, L. J., College, B., Mukherjee, K., \& Santerre, R. E. (2006). Market structure and technical efficiency in the hospital services industry: A DEA approach. Medical Care Research and Review, 63, 499-524. https://doi.org/10.1177/1077558706288842

Besstremyannaya, G. (2013). The Impact of Japanese Hospital Financing Reform on Hospital Efficiency: A Difference-in-difference Approach. Japanese Economic Review, 64, 337-362. https://doi.org/10.1111/j.1468-5876.2012.00585.x

Blank, J. L., \& Valdmanis, V. G. (2010). Environmental factors and productivity on Dutch hospitals: A semi-parametric approach. Health Care Manag Sci, 13, 27-34. https://doi.org/10.1007/s10729-009-9104-0

Blank, J. L., \& Vanhulst, B. L. (2011). Governance and performance: The performance of Dutch hospitals explained by governance characteristics. Journal of Medical Systems, 35, 991-999. https://doi.org/10.1007/s10916-010-9437-8

Butler, T. W., \& Li, L. (2005). The Utility of Returns to Scale in DEA Programming: An Analysis of Michigan Rural Hospitals. European Journal of Operational Research, 161, 469-477. https://doi.org/10.1016/j.ejor.2003.09.019

Charnes, A., Cooper, W. W., \& Rhodes, E. (1979). Mearuring the Efficient of Decision-making Units. European Journal of Operational Research, 3, 429-444. https://doi.org/10.1016/0377-2217(79)90229-7

Chen, A., Wang, Y. C., \& Shao, B. (2005). Measurement and sources of overall and input inefficiencies: Evidences and implications in hospital services. European Journal of Operational Research, 161, 447-468. https://doi.org/10.1016/j.ejor.2003.09.017

Cheng, X. P., \& Wu, Z. H. (2010). The Analysis on the Distribution of the Resources in the Comprehensive Public Hospitals of the Second Grade in Hangzhou City. Modern Hopital Management, 8, 14-15.

Chowdhury, H., Zelenyuk, V., Laporte, A., \& Wodchis, W. P. (2014). Analysis of productivity, 
efficiency and technological changes in hospital services in Ontario: How does case-mix matter? $\begin{array}{llllll}\text { International Journal of Production } & \text { Economics, } & 150, & \text { 74-82. }\end{array}$ https://doi.org/10.1016/j.ijpe.2013.12.003

Chuang, C. L., Chang, P. C., \& Lin, R. H. (2011). An Efficiency Data Envelopment Analysis Model Reinforced by Classification and Regression Tree for Hospital Performance Evaluation. Journal of Medical Systems, 35, 1075-1083. https://doi.org/10.1007/s10916-010-9598-5

Chustz, M. (2012). Financial Performance Monitoring of the Technical Efficiency of Critical Access Hospitals: A Data Envelopment Analysis and Logistic Regression Modeling Approach Practitioner Application. Journal of Healthcare Management, 57, 212-213.

Clement, J., Valdmanis, V., Bazzoli, G., Zhao, M., \& Chukmaitov, A. (2008). Is more better? An analysis of hospital outcomes and efficiency with a DEA model of output congestion. Health Care Management Science, 11, 67-77. https://doi.org/10.1007/s10729-007-9025-8

Cui, Y. H., \& He, Q. C. (2008). Research on Evaluating the Efficieney of General Hospital in DEA Programming. Chinese Health Economics, 25, 18-21.

Czypionka, T., Kraus, M., Mayer, S., \& Rohrling, G. (2014). Efficiency, ownership, and financing of hospitals: The case of Austria. Health Care Management Science, 17, 331-347. https://doi.org/10.1007/s10729-013-9256-9

Dai, J. F. (2005). Performance Research in Hospitals. Huazhong University of Science and Technology, Wuhan, Hubei.

Daraio, C., \& Simar, L., (2007). Advanced robust and nonparametric methods in efficiency analysis: Methodology and applications. Springer-Verlag New York Inc, New York.

Dimas, G., Goula, A., \& Soulis, S. (2012). Productive Performance and its Components in Greek Public Hospitals. Operational Research, 12, 15-27. https://doi.org/10.1007/s12351-010-0082-2

Dong, S. P. (2010). Study on the Economic Efficiency of Scale and its Determinants in County General Hospitals. Huazhong University of Science and Technology, Wuhan, Hubei.

Du, J., Wang, J., Chen, Y., Chou, S. Y., \& Zhu, J. (2014). Incorporating Health Outcomes in Pennsylvania Hospital Efficiency: An Additive Super-efficiency DEA Approach. Annals of Operations Research, 221, 161-172. https://doi.org/10.1007/s10479-011-0838-y

Fan, X. J., Ke, X. Q., Wang, H. M., Chen, Z., \& Chen, H. (2004). Correlation Between Medical Market Structure and Hospital Efficiency in the Hangzhou Area. Chinese Journal of Hospital Administration, 20, 417-420.

Fareed, N., Ozcan, Y. A., \& DeShazo, J. P. (2012). Hospital electronic medical record enterprise application strategies: Do they matter? Health Care Management Review, 37, 4-13. https://doi.org/10.1097/HMR.0b013e318239f2ff

Ferrier, G. D., Rosko, M. D., \& Valdmanis, V. G. (2006). Analysis of uncompensated hospital care using a DEA model of output congestion. Health Care Management Science, 9, 181-188. https://doi.org/10.1007/s10729-006-7665-8 
Ferrier, G. D., \& Trivitt, J. S. (2013). Incorporating quality into the measurement of hospital efficiency: A double DEA approach. Journal of Productivity Analysis, 40, 337-355. https://doi.org/10.1007/s11123-012-0305-z

Flokou, A., Kontodimopoulos, N., \& Niakas, D. (2011). Employing post-DEA Cross-evaluation and Cluster Analysis in a Sample of Greek NHS Hospitals. Journal of Medical Systems, 35, 1001-1014. https://doi.org/10.1007/s10916-010-9533-9

Gai, R. Y., Zhou, C. C., Xu, L. Z., Zhu, M., Wang, X. Z., Li, S. X., .. Tang, W. (2010). Health resource allocation and productive efficiency of Chinese county hospitals: Data from 1993 to 2005. Bioscience Trends, 4, 218-224.

Garcia-Lacalle, J., \& Martin, E. (2010). Rural vs. Urban Hospital Performance in a "Competitive" Public Health Service. Social Science and Medicine, 71, 1131-1140. https://doi.org/10.1016/j.socscimed.2010.05.043

Gautam, S., Hicks, L., Johnson, T., \& Mishra, B. (2013). Measuring the Performance of Critical Access Hospitals in Missouri Using Data Envelopment Analysis. Journal of Rural Health, 29, 150-158.

Geng, S. S. (2012). Preliminary Construction of Evaluation Model on Bed Utilization Efficiency in General Hospitals. Huazhong University of Science and Technology, Wuhan, Hubei.

Gok, M. S., \& Sezen, B. (2013). Analyzing the Ambiguous Relationship between Efficiency, Quality and Patient Satisfaction in Healthcare Services: The case of Public Hospitals in Turkey. Health Policy, 111, 290-300. https://doi.org/10.1016/j.healthpol.2013.05.010

Gok, S. M., \& Sezen, B. (2012). Capacity inefficiencies of teaching and non-teaching hospitals. Service Industries Journal, 32, 2307-2328. https://doi.org/10.1080/02642069.2011.582495

Goncalves, A. C., Noronha, C. P., Lins, M. P., \& Almeida, R. M. (2007). Data Envelopment Analysis for Evaluating Public Hospitals in Brazilian State Capitals. Revista de Saúde Publica, 41, 427-435.

Groff, J. E., Lien, D., \& Su, J. W. (2007). Measuring efficiency gains from hospital mergers. Research in Healthcare Financial Management, 11, 77-90.

Guo, X. R. (2012). Efficiency of Public Hospitals in China and Its Influencing Factors. Shangdong University, Jinan, Shangdong.

Halkos, G. E., \& Tzeremes, N. G. (2011). A Conditional Nonparametric Analysis for Measuring the Efficiency of Regional Public Healthcare Delivery: An Application to Greek Prefectures. Health Policy, 103, 73-82. https://doi.org/10.1016/j.healthpol.2010.10.021

Han, X. M., Li, J., Wang, L. X., Hu, Q., Shao, Y. W., Yao, Q., ... Chen, Y. C. (2014). Evaluation of Tertiary Hospitals Technology Efficiency Based on Data Envelopment Analysis in Gansu Province. Chongqing Medicine, 43, 994-996.

Harrison, J. P., Coppola, M. N., \& Wakefield, M. (2004). Efficiency of Federal Hospitals in the United

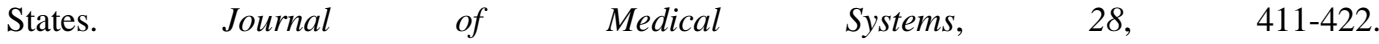
https://doi.org/10.1023/B:JOMS.0000041168.28200.8c 
Harrison, J. P., \& Lambiase, L. R. (2007). The Improving Efficiency of University Health Consortium Hospitals. Journal of Public Budgeting, Accounting \& Financial Management, 19, 385-399.

Harrison, J. P., \& Meyer, S. (2014). Measuring efficiency among US federal hospitals. Health Care Manag (Frederick), 33, 117-127. https://doi.org/10.1097/hcm.0000000000000005

Harrison, J. P., Ogniewski, R., \& Hoelscher, S. (2009). The Improving Efficiency of Critical Access Hospitals. Health Care Manag (Frederick), 28, 209-217. https://doi.org/10.1097/hcm.0b013e3181b3e968

Harrison, J. P., \& Ogniewski, R. J. (2005). An efficiency analysis of Veterans Health Administration hospitals. Military Medicine, 170, 607-611. https://doi.org/10.7205/MILMED.170.7.607

Harrison, J. P., \& Sexton, C. (2006). The improving efficiency frontier of religious not-for-profit hospitals. Hospital Topics, 84, 2-10. https://doi.org/10.3200/HTPS.84.1.2-10

Herwartz, H., \& Strumann, C. (2012). On the effect of prospective payment on local hospital competition in Germany. Health Care Management Science, 15, 48-62. https://doi.org/10.1007/s10729-011-9180-9

Herwartz, H., \& Strumann, C. (2014). Hospital Efficiency under Prospective Reimbursement Schemes: An Empirical Assessment for the case of Germany. European Journal of Health Economics, 15, 175-186. https://doi.org/10.1007/s10198-013-0464-5

Hsieh, H. M., Clement, D. G., \& Bazzoli, G. J. (2010). Impacts of Market and Organizational Characteristics on Hospital Efficiency and Uncompensated Care. Health Care Management Review, 35, 77-87. https://doi.org/10.1097/HMR.0b013e3181c09956

Hu, H. H., Qi, Q. H., \& Yang, C. H. (2012). Analysis of hospital technical efficiency in China: Effect of health insurance reform. China Economic Review, 23, 865-877. https://doi.org/10.1016/j.chieco.2012.04.008

Huang, S., Feng, Q. M., Li, Y. N., Qi, S. C., Jing, Y. Z., Mo, X. X., \& You, J. P. (2014). Data Envelopment Analysis on Efficiency of County-level Public Hospitals in Guangxi. Chinese Journal of Public Health, 30, 653-656.

Huang, X. H., Meng, F. L., \& Wang, X. H. (2010). Application of Data Envelopment Analysis in Assessing the Technical Efficiency and Quality of Hospitals. Health Research, 30, 280-282.

Huo, H. Y., \& Wu, W. M. (2012). Study of County Hospitals Efficiency in Guangxi Based on Data envelopment Analysis. Chinese Health Economics, 29, 884-886.

Jat, T. R., \& Sebastian, M. S. (2013). Technical efficiency of public district hospitals in Madhya Pradesh, India: A data envelopment analysis. Global Health Action, 6, 1-8.

Jehu-Appiah, C., Sekidde, S., Adjuik, M., Akazili, J., Almeida, S. D., Nyonator, F., ... Kirigia, J. M. (2014). Ownership and Technical Efficiency of Hospitals: Evidence from Ghana Using Data Envelopment Analysis. Cost Eff Resour Alloc, 12, 9. https://doi.org/10.1186/1478-7547-12-9

Jiang, H. (2013). Study of the Resource Allocation and Operational Mechanism of Public Hospitals in Guangzhou. Jinan Univeristy, Guangzhou, Guangdong. 
Karagiannis, R., \& Velentzas, K. (2012). Productivity and Quality Changes in Greek Public Hospitals. Operational Research, 12, 69-81. https://doi.org/10.1007/s12351-010-0080-4

Kawaguchi, H., Tone, K., \& Tsutsui, M. (2014). Estimation of the efficiency of Japanese hospitals using a dynamic and network data envelopment analysis model. Health Care Management Science, 17, 101-112. https://doi.org/10.1007/s10729-013-9248-9

Kibambe, J. N., \& Kocht, S. F. (2007). DEA applied to a Gauteng sample of public hospitals. South African Journal of Economics, 75, 351-368. https://doi.org/10.1111/j.1813-6982.2007.00125.X

Kirigia, J. M., \& Asbu, E. Z. (2013). Technical and Scale Efficiency of Public Community Hospitals in Eritrea: An Exploratory Study. Health Econ Rev, 3, 6. https://doi.org/10.1186/2191-1991-3-6

Kirigia, J. M., Emrouznejad, A., Cassoma, B., Asbu, E. Z., \& Barry, S. (2008). A Performance Assessment Method for Hospitals: The Case of Municipal Hospitals in Angola. Journal of Medical Systems, 32, 509-519. https://doi.org/10.1007/s10916-008-9157-5

Kounetas, K., \& Papathanassopoulos, F. (2013). How efficient are Greek hospitals? A case study using a double bootstrap DEA approach. European Journal of Health Economics, 14, 979-994. https://doi.org/10.1007/s10198-012-0446-z

Kristensen, T., Bogetoft, P., \& Pedersen, K. M. (2010). Potential gains from hospital mergers in Denmark. Health Care Management Science, 13, 334-345. https://doi.org/10.1007/s10729-010-9133-8

Lee, K. H., Yang, S. B., \& Choi, M. (2009). The Association between Hospital Ownership and Technical Efficiency in a Managed Care Environment. Journal of Medical Systems, 33, 307-315. https://doi.org/10.1007/s10916-008-9192-2

Lee, K. S., Chun, K. H., \& Lee, J. S. (2008). Reforming the Hospital Service Structure to Improve Efficiency: Urban Hospital Specialization. Health Policy, 87, 41-49. https://doi.org/10.1016/j.healthpol.2007.10.003

Lei, H. C., Zhou, Z. N., Xie, X. Q., Tan, Z. J., Liu, R. M., Wang, Q., .. Li, Z. P. (2014). Study on Tertiary Hospitals's Optimal Scale Based on Data Envelopment Analysis. Chinese Hospital Management, 34, 11-14.

Li, D.N., Ma, Y., Wang, H. (2007). Use of DEA in Evaluating the Efficiency of the Secondary Hospitals in Harbin. Medicine World, 97-99.

Li, H., Dong, S. P., \& Liu, T. F. (2014). Relative efficiency and productivity: A preliminary exploration of public hospitals in Beijing, China. BMC Health Services Research, 14. https://doi.org/10.1186/1472-6963-14-158

Li, L. (2007). The Efficiency of Hospitals in Hunan Province Via Data Envelopment Analysis (DEA) Model. Central South University, Changsha, Hunan.

Li, L., \& Wang, J. (2008). The Technical Efficiency Analysis on China's Public Hopital: Application of Data Envelopment Analysis. Chinese Journal of Health Policy, 1, 51-57.

Li, X. W., Xu, S. X., \& Zhang, L. (2011). Analysis of Scale Economies of GeneraI Hospitals Based on Published by SCHOLINK INC. 
Efficiency. Chinese Hospital Management, 31, 65-68.

Li, Y. N. (2013). Study of the Development and Efficiency Evaluation of County Hospitals in Shandong. Qindao University Qindao, Shangdong.

Liang, J. F., \& Shen, Y. (2006). Performance Evaluation of Secondary or Above Hospitals Based on Data Envelopment Analysis (DEA) in Zhejiang Province. Chinese Hospital Management, 26, 108-109.

Lin, H., \& Jin, X. R. (2007). Government investment and changes of hospitals efficiency in China. Economist.

Lin, S. J., \& Qiu, H. Z. (2014). Study on the Comparison of Input-output Efficiency in Hospital of Traditional Chinese Medicine of Grade Three in Guangdong Province. Modern Hospital Management, 12, 18-21.

Linna, M., Häkkinen, U., Peltola, M., Magnussen, J., Anthun, K. S., Kittelsen, S., ... Rehnberg, C. (2010). Measuring cost efficiency in the Nordic Hospitals-a cross-sectional comparison of public hospitals in 2002. Health Care Management Science, 13, 346-357. https://doi.org/10.1007/s10729-010-9134-7

Linna, M., Hakkinen, U., \& Magnussen, J. (2006). Comparing hospital cost efficiency between Norway and Finland. Health Policy, 77, 268-278. https://doi.org/10.1016/j.healthpol.2005.07.019

Liu, H. J. (2013). Study of Efficiency Evaluation of Health Care Services of Medical Institutions in Beijing A District. Nanchang University, Nanchang, Jiangxi.

Liu, L., He, X. Q., \& Wang, Z. (2010). The Application of Data Envelopment Analysis in Optimal Health Resource Allocation-A Case Study of Township Hospitals in Chongqing. Journal of Southwest China Normal University (Natural Science Edition), 35, 84-89.

Liu, Y. Q., Pan, X. P., Liao, J., Kuang, J. Q., Quan, T., Zhong, R. B., ... Wen, Y. S. (2011). Comparison of Different Data Envelopment Analysis Models in EvaInating Hospitais' Technical Efficiency. Chinese Health Economics, 30, 65-67.

Liu, Y. X. (2013). Evaluation of County Public Hospitals efficiency in Chengdu Based on Data Envelopment Analysis. Zhi Shi Jing Ji, 33-34.

Lobo, M. S. C., Ozcan, Y. A., Lins, M. P. E., Silva, A. C. M., \& Fiszman, R. (2014). Teaching Hospitals in Brazil: Findings on Determinants for Efficiency. International Journal of Healthcare Management, 7, 60-68. https://doi.org/10.1179/2047971913Y.0000000055

Lu, W. J., Yang, Q., \& Feng, Z. C. (2012). Evaluation on the Efficiency of 23 Hospitals in Wuhan by DEA. Medicine and Society, 25, 70-72.

Luo, C. Z. (2009). An investigation on the price distortion of the medical services in hospitals at all levels in Shanghai. Shanghai Jiaotong University, Shanghai.

Luo, X., Chen, T., \& Liu, W. F. (2004). An Application of cone ratio DEA Model in the relative evaluation of hospital, China Operations Research Society to the 7th Academic Communication (pp. 342-343). Qingdao, Shandong. 
Ma, D. (2007). Performance and Scale Economy Analysis for Ministry's Gneral Hospital of China. Dalian Medical University, Dalian, Liaoning.

Ma, T., \& Petr, D. (2005). Main determinants of costs and the feasibility of enhancing the performance of hospital care providers-The case of Slovenia Sixth International Conference on "Enterprise in Transition" (pp. 205-218). Hrvatska, Croatia.

Mao, Y. N. (2013). A study of Operating Efficiency and Productivity Changes for 52 Tertiary General Hospitals. Peking Union Medical College, Beijing.

Masiye, F. (2007). Investigating health system performance: An application of data envelopment analysis to Zambian hospitals. BMC Health Services Research, 7. https://doi.org/10.1186/1472-6963-7-58

Medin, E., Anthun, K. S., Hakkinen, U., Kittelsen, S. A. C., Linna, M., Magnussen, J., ... Rehnberg, C. (2011). Cost efficiency of university hospitals in the Nordic countries: A cross-country analysis. European Journal of Health Economics, 12, 509-519. https://doi.org/10.1007/s10198-010-0263-1

Meng, X. Z., Liu, G. H., Nie, H. B., \& Zhu, M. F. (2009). Application of Data envelopment analysis in the Evaluation of Medical Institutions. Clinical Jounal of Chinese Medicine, 1, 77-80.

Mitropoulos, P., Mitropoulos, I., \& Sissouras, A. (2013). Managing for efficiency in health care: The case of Greek public hospitals. European Journal of Health Economics, 14, 929-938. https://doi.org/10.1007/s10198-012-0437-0

Nayar, P., \& Ozcan, Y. A. (2008). Data Envelopment Analysis Comparison of Hospital Efficiency and Quality. Journal of Medical Systems, 32, 193-199. https://doi.org/10.1007/s10916-007-9122-8

Nayar, P., Ozcan, Y. A., Yu, F., \& Nguyen, A. T. (2013). Benchmarking Urban Acute Care Hospitals: Efficiency and Quality perspectives. Health Care Management Review, 38, 137-145. https://doi.org/10.1097/HMR.0b013e3182527a4c

Nedelea, I. C., \& Fannin, J. M. (2013). Analyzing cost efficiency of Critical Access Hospitals. Journal of Policy Modeling, 35, 183-195. https://doi.org/10.1016/j.jpolmod.2012.10.002

Ng, Y. C. (2011). The productive efficiency of Chinese hospitals. China Economic Review, 22, 428-439. https://doi.org/10.1016/j.chieco.2011.06.001

O’Neill, L., Rauner, M., Heidenberger, K., \& Kraus, M. (2008). A cross-national comparison and taxonomy of DEA-based hospital efficiency studies. Socio-Economic Planning Sciences, 42, 158-189. https://doi.org/10.1016/j.seps.2007.03.001

Osei, D., d'Almeida, S., George, M. O., Kirigia, J. M., Mensah, A. O., \& Kainyu, L. H. (2005). Technical Efficiency of Public District Hospitals and Health Centres in Ghana: A Pilot Study. Cost Eff Resour Alloc, 3, 9. https://doi.org/10.1186/1478-7547-3-9

Ozcan, Y. A., Lins, M. E., Lobo, M. S. C., da Silva, A. C. M., Fiszman, R., \& Pereira, B. B. (2010). Evaluating the performance of Brazilian university hospitals. Annals of Operations Research, 178, 247-261. https://doi.org/10.1007/s10479-009-0528-1

Pang, H. M., \& Wang, X. W. (2010). Evaluating Efficiency of Level III General Hospitals in China Published by SCHOLINK INC. 
Based on DEA Malmquist Index. Chinese Hospital Management, 30, 35-37.

Pang, R. Z. (2006). Empirical Study on Hospitals Efficiency in Cities-Based on the Two-Stage DEA Model. Nankai Economic Studies, 71-81.

Peng, Y. B. (2012). The Research of the Service Efficiency and Approrite Scale of 38 Hospitals in the Region of Northern Xinjiang. Xinjiang Medical University, Urumqi, Xinjiang.

Peng, Y. B., Ma, L., Kade'er, G., \& Ding, Y. (2012). Data Envelopment Analysis-based efficiency analysis in 28 County-level hospitals In northern Xinjiang. Chinese Health Resources, 15, 169-170.

Pham, T. L. (2011). Efficiency and productivity of hospitals in Vietnam. J Health Organ Manag, 25, 195-213. https://doi.org/10.1108/14777261111134428

Pilyavsky, A., \& Staat, M. (2006). Health care in the CIS countries: The case of hospitals in Ukraine. Eur J Health Econ, 7, 189-195. https://doi.org/10.1007/s10198-006-0351-4

Polyzos, N. (2012). A three-year Performance Evaluation of the NHS Hospitals in Greece. Hippokratia, $16,350-355$.

Puenpatom, R. A., \& Rosenman, R. (2008). Efficiency of Thai provincial public hospitals during the introduction of universal health coverage using capitation. Health Care Management Science, 11, 319-338. https://doi.org/10.1007/s10729-008-9057-8

Qin, J. Z. (2011). The Study on Input-output of the County Hospital in Shandong Provice. Shandong University, Jinan, Shandong.

Ramanathan, R. (2005). Operations assessment of hospitals in the Sultanate of Oman. International Journal of Operations \& Production Management, 25, 39-54. https://doi.org/10.1108/01443570510572231

Rego, G., Nunes, R., \& Costa, J. (2010). The challenge of corporatisation: The experience of Portuguese public hospitals. European Journal of Health Economics, 11, 367-381. https://doi.org/10.1007/s10198-009-0198-6

Roh, C. Y., Moon, M. J., \& Jung, K. (2013). Efficiency Disparities among Community Hospitals in Tennessee: Do Size, Location, Ownership, and Network Matter? Journal of Health Care for the Poor and Underserved, 24, 1816-1833. https://doi.org/10.1353/hpu.2013.0175

Rosko, M. D., \& Mutter, R. L. (2008). Stochastic Frontier Analysis of Hospital Inefficiency. Medical Care Research and Review, 65, 131-166. https://doi.org/10.1177/1077558707307580

Siciliani, L. (2006). Estimating Technical Efficiency in the Hospital Sector with Panel Data: A Comparison of Parametric and Non-parametric Techniques. Applied Health Economics and Health Policy, 5, 99-116. https://doi.org/10.2165/00148365-200605020-00004

Simões, P., \& Marques, R. (2011). Performance and congestion analysis of the portuguese hospital services. Central European Journal of Operations Research, 19, 39-63. https://doi.org/10.1007/s10100-009-0122-2

Simar, L., \& Wilson, P. W. (1998). Sensitivity analysis of efficiency scores: How to bootstrap in 
nonparametric frontier models. Management Science, 44, 49-61. https://doi.org/10.1287/mnsc.44.1.49

Song, W. C., He, Y., \& Wu, Y. X. (2011). Input-output Efficiency Analysis of Jiangxi Province Secondary First-class Hospitals. Chinese Health Economics, 30, 57-58.

Staat, M. (2006). Efficiency of hospitals in Germany: A DEA-bootstrap approach. Applied Economics, 38, 2255-2263. https://doi.org/10.1080/00036840500427502

Steinmann, L., Dittrich, G., Karmann, A., \& Zweifel, P. (2004). Measuring and Comparing the (In)Efficiency of German and Swiss Hospitals. European Journal of Health Economics, 5, 216-226. https://doi.org/10.1007/s10198-004-0227-4

Sulku, S. N. (2012). The health sector reforms and the efficiency of public hospitals in Turkey: Provincial markets. European Journal of Public Health, 22, 634-638. https://doi.org/10.1093/eurpub/ckr163

Sun, Q., Guo, X. R., Meng, Q. Y., \& Cheng, G. (2012). DEA Efficiency Analysis of Ministry of Health's 57 Hospitals. Chinese Health Economics, 31, 72-74.

Tan, Z. J., Lei, H. C., Mao, A. Y., Lin, J. Y., \& Yue, X. P. (2014). Quantitative Study on the Optimal Scales of Secondary Public Hospitals. Chinese Hospitals, 18, 25-27.

Tan, Z. J., Lin, J. Y., Lei, H. C., Mao, A. Y., Yue, X. P., \& Zhou, Z. N. (2014). Study On optimal Scaling of Secondary Public General Hospitals in Beijing. Chinese Journal of Hospital Administration, 30, 385-395.

Tang, L., Zhang, W., Yuan, H. Y., \& Tao, R. (2014). Data Envelopment Analysis-based Comparative Analysis for Operational Efficiency of Upper First-Class General Hospitals in Beijing and Shanghai. Journal of Shanghai Jiao Tong University ( Medical Science), 34, 95-99.

Thompson, M. A., Huerta, T. R., \& Ford, E. W. (2012). Mandatory Insurance Coverage and Hospital Productivity in Massachusetts: Bending the Curve? Health Care Management Review, 37, 294-300. https://doi.org/10.1097/HCM.0b013e318242d0ba

Tian, L. N. (2013). Evaluation of Second-grade Hospitals in Henan Province Based on the RelatiVe Efnciency of DEA. Journal of Henan Medical College for Staff and Workers, 25, 221-223.

Tiemann, O., \& Schreyögg, J. (2009). Effects of Ownership on Hospital Efficiency in Germany. Business Research, 2, 115-145. https://doi.org/10.1007/BF03342707

Tiemann, O., \& Schreyögg, J. (2012). Changes in hospital efficiency after privatization. Health Care Management Science, 15, 310-326. https://doi.org/10.1007/s10729-012-9193-z

Tlotlego, N., Nonvignon, J., Sambo, L. G., Asbu, E. Z., \& Kirigia, J. M. (2010). Assessment of productivity of hospitals in Botswana: A DEA application. International Archives of Medicine, 3, 27. https://doi.org/10.1186/1755-7682-3-27

Tu, G. P., Leng, B. B., Wu, J. J., \& Li, L. Q. (2011). Empirical Analysis of resource utilization efficiency on DEA in Public Traditional Chinese Medicine Hospitals. Chinese Health Economics, 28, 189-194. 
Valdmanis, V., Kumanarayake, L., \& Lertiendumrong, J. (2004). Capacity in Thai public hospitals and the production of care for poor and nonpoor patients. Health Services Research, 39, 2117-2134. https://doi.org/10.1111/j.1475-6773.2004.00335.x

Valdmanis, V. G., Rosko, M. D., \& Mutter, R. L. (2008). Hospital quality, efficiency, and input slack differentials. Health Services Research, 43, 1830-1848. https://doi.org/10.1111/j.1475-6773.2008.00893.x

Varabyova, Y., \& Schreyogg, J. (2013). International comparisons of the technical efficiency of the hospital sector: Panel data analysis of OECD countries using parametric and non-parametric approaches. Health Policy, 112, 70-79. https://doi.org/10.1016/j.healthpol.2013.03.003

Wang, B. Y., \& Fang, P. Q. (2014). Analysis on Operation Efficiency of Collaborative Management of Medical Institutions in County and Township Areas Based on DEA Method. Medicine and Society, 27, 15-18.

Wang, H., Ma, Y., Li, B., \& Li, D. N. (2006). Application of DEA in evaluating the efficiency of the Tertiary Hopsitals. Chinese Journal of Hospital Statistics, 13, 289-292.

Wang, J. S., Zhang, Z. W., \& Dong, S. P. (2010). Malmquist Index-based Analysis for Total Factor Productivity of Grade-three Hospitals in Beijing. Chinese health Quality Management, 18, 56-58.

Wang, J. S., Zhang, Z. W., \& Dong, S. P. (2011). DEA-based Comparative Analysis for Operational Efficiency of Grade-three Hospitals between Beijing and Shanghai. Chinese health Quality Management, 18, 48-50, 55.

Wang, L. J., \& Yin, A. T. (2013). To Evaluate the Tradional Chinese Medical Service Efficiency of the County Traditional Chinese Medicine Hospitals in Shangdong Province. Chinese Health Economics, 32, 81-83.

Wang, M., Li, J. W., Luo, C., \& Fang, G. G. (2013). The Danamic Analysis on the Total Factor Productivity of Hospitals of Traditional Chinese Medicine from 2002 to 2012 in Beijing. Chinese Health Economics, 32, 78-80.

Wang, T. Q., Ma, Y., Li, B., Yang, J. B., Wang, H., \& Li, D. N. (2006). The Evaluation on Relative Efficiencies of the Tertiary Hospitals in Heilongjiang by the Data Envelopment Analysis (or DEA). Chinese Health Economics, 25, 64-66.

Wang, W., Chen, S. X., Peng, X. M., Qu, Z. T., Chen, S. R., \& Tian, Y. L. (2008). Efficiency Analysis of Public Hospitals in Guangdong Province. Chinese Hospital Management, 28, 16-19.

Wang, W., \& Pan, J. X. (2013). Analysis on the Efficiency of 14 Division-level Hospitals of Xinjiang Production and Construction Corps Based on DEA Model. Chinese Health Economics, 32, 78-80.

Wei, C. K. (2006). Measuring Efficiency and Productivity Change in Taiwan Hospitals: A Nonparametric Frontier Approach. Journal of American Academy of Business, Cambridge, 10, 317-323.

Wei, C. K., Chen, L. C., Li, R. K., \& Tsai, C. H. (2011). Using the DEA-R model in the hospital industry to study the pseudo-inefficiency problem. Expert Systems with Applications, 38, 
2172-2176. https://doi.org/10.1016/j.eswa.2010.08.003

Weng, S. J., Wu, T., Blackhurst, J., \& Mackulak, G. (2009). An extended DEA model for hospital performance evaluation and improvement. Health Services \& Outcomes Research Methodology, 9, 39-53. https://doi.org/10.1007/s10742-008-0042-y

Wu, J. J. (2009). Analysis and Evaluation of the Fundamental Mode on Public hospitals Competitive. Nanchang University, Nanchang, Jiangxi.

Wu, X. D. (2009). The Assessment on Efficiency of General Hospital Using DEA\&SFA Models. Dalian Medical University, Dalian, Liaoning.

Wu, Y. (2011). Analysis on the Economical Running and Efficiency of 20 Central Hospitals in Shanghai from 1999 to 2009 (Unpublished Master). Second Military Medical University, Xian, Shanxi.

Xia, Q. R., Xu, J., \& Hang, L. (2009). Study on Input-Output Emciency of Hospital Based on DEAHP Model. China Medical Herald, 6, 124-127.

Xu, H. C. (2010). Study on Performance Measurements of General Hospitals in Wuhan City. Huazhong University of Science and Technology, Wuhan, Hubei.

Xu, Y. C., Wang, R. H., \& Fu, G. J. (2013). Efficiency evaluation of County-level Public Hospital Based on Data Envelopment Analysis. Chongqing Medicine, 3939-3944.

Yan, C. X., \& Dong, S. F. (2005). Analysis of Input and Output Efficiency of Hospitals in Wuhan. Chinese Hospital Management, 25, 22-26.

Yang, J. Q., \& Zeng, W. (2014). The trade-offs between efficiency and quality in the hospital production: Some evidence from Shenzhen, China. China Economic Review, 31, 166-184. https://doi.org/10.1016/j.chieco.2014.09.005

Yu, L. X., Li, L. Q., Luo, Y. F., \& Zhang, W. B. (2012). Analysis and Thinking of Health Resource Collocation and Science Efficiency of Public Hospitals. Chinese Hospital Management, 32, 11-12.

Yuan, C. H., Wang, S. Y., Li, G. Y., Ge, R. W., Dong, S. S., Jia, L. Y., \& Fu, S. H. (2013). Performance and Government Funding of County Hospitals in China: Based on the Survey of 131 Hospitals in 4 Provinces. Chinese Journal of Health Policy, 6, 51-56.

Yusefzadeh, H., Ghaderi, H., Bagherzade, R., \& Barouni, M. (2013). The Efficiency and Budgeting of Public Hospitals: Case Study of Iran. Iranian Red Crescent Medical Journal, 15, 393-399. https://doi.org/10.5812/ircmj.4742

Zaim, S., Bayyurt, N., Turkyilmaz, A., Solakoglu, N., \& Zaim, H. (2007). Measuring and Evaluating Efficiency of Hospitals Through Total Quality Management: A Multi-Criteria Data Envelopment Analysis Model. Journal of Transnational Management, 12, 77-97. https://doi.org/10.1300/J482v12n04_05

Zere, E., Mbeeli, T., Shangula, K., Mandlhate, C., Mutirua, K., Tjivambi, B., \& Kapenambili, W. (2006). Technical efficiency of district hospitals: Evidence from Namibia using data envelopment analysis. Cost Eff Resour Alloc, 4, 5. https://doi.org/10.1186/1478-7547-4-5 
Zhang, X. (2013). Analysis of the Economic Operating Efficiency and Impact Factors of Shanghai Suburban Secondary Hospitals from 2003 to 2011. Second Military Medical University, Shanghai. Zhang, Y. (2011). Research on the Appropriate Size of County Hospitals in Anhui Provice. Anhui Medical Unversity, Hefei, Anhui.

Zhang, Y. Q., Tang, G. L., Wang, W. C., \& Yi, D. (2011). Analysis of Input and Output Efficiency of above and in County-level Hospitals Chongqing. Chinese Hospital Management, 31, 30-32.

Zhao, C. C., Xu, H. Q., \& Zhang, Y. (2010). Analyzing the Suitable Scale for County Hospitals. Chinese Health Service Management, 27, 796-814.

Zhong, R. B. (2010). Technical and Cost Inefficiency of Hospital: Data Envelopment Analysis and Stochastic Frontier Analysis. Chongqing Medical University, Chongqing.

Zhong, R. B., Zhang, J., Zhong, X. N., Liao, J., Han, L., Zhang, J. Y., \& Cao, Q. (2010). Discussing the Application of Data Envelopment Analysis Model in Evaluating Hospitals' efficiency. Chinese Health Service Management, 27, 372-374.

Zhou, J. (2013). Research on optimization of evaluation model on hospitals' medical resources utilization efficiency. Huazhong University of Science and Technology, Wuhan, Hubei. 